\title{
The Home Physical Activity Environment and Adolescent BMI, Physical Activity, and TV Viewing: Disparities Across a Diverse Sample
}

\author{
Marla E. Eisenberg • Nicole I. Larson • Jerica M. Berge • \\ Chelsey M. Thul • Dianne Neumark-Sztainer
}

Received: 23 April 2014 / Revised: 21 July 2014 / Accepted: 23 July 2014 / Published online: 15 August 2014

(C) W. Montague Cobb-NMA Health Institute 2014

\begin{abstract}
Objective Characteristics of the home and family have been associated with adolescents' BMI and physical and sedentary activity, but few studies have examined how these characteristics vary across ethnic/ethnic groups. This study explores whether recommendations for activity promotion are equally relevant to different adolescent populations.

Design Participants included 2,374 adolescents and their parent(s), recruited through 20 public schools in Minneapolis/St. Paul, MN, in 2009-2010. Ethnic/racial groups included African American, Asian (primarily Hmong), East African, Hispanic, Native American, White, and mixed/other race. Linear regression analysis modeled adolescents' BMI $z$-scores and physical and sedentary activity based on six measures of the family/home activity environment, adjusted for covariates. Interactions of ethnicity/race and family/home environment were tested.

Results All six family/home environment measures varied significantly across ethnicity/race. Family/home variables were significantly associated with adolescent physical activity and TV viewing in the expected directions, and these
\end{abstract}

M. E. Eisenberg $(\triangle) \cdot$ C. M. Thul

Division of General Pediatrics and Adolescent Health, Department of Pediatrics, University of Minnesota, 717 Delaware St. SE, Minneapolis, MN 55414, USA

e-mail: eisen012@umn.edu

N. I. Larson · D. Neumark-Sztainer

Division of Epidemiology and Community Health, School of Public Health, University of Minnesota, 1300 South 2nd St., Minneapolis, MN 55454, USA

J. M. Berge

Department of Family Medicine and Community Health, University of Minnesota, 717 Delaware St. SE Room 424, Minneapolis, MN 55112, USA relationships were consistent across ethnic/racial groups in two thirds of the models. However, in one third of the cases, these associations were modified by ethnicity/race. For example, home access to a greater number of media devices was significantly associated with more TV viewing $(\beta=.40$, $p=.015$ ) only among White youth.

Conclusion Health promotion recommendations for adolescent physical activity are largely relevant across ethnic/racial groups. However, given differences found in the family/home environments of adolescents, cultural sensitivity is recommended in discussing these issues, and tailored recommendations may be appropriate for select groups or behaviors. Further mixed methods research is warranted to help identify key messages for specific groups.

Keywords Adolescents · Weight · Physical activity · Sedentary activity $\cdot$ Family

\section{Introduction}

The high prevalence of obesity among youth and the growing disparities across population subgroups are of great public health concern [1-3]. In particular, substantial differences in body mass index (BMI) are evident across ethnic and racial groups. According to the Youth Risk Behavior Surveillance Study (YRBSS), $13 \%$ of high school students in the USA are categorized as obese and an additional $15 \%$ are overweight with higher prevalences among Black and Hispanic students than among White students [4]. In our previous work, we found the prevalence of obesity among Hispanic, Asian (primarily Hmong), and Native American adolescent boys to be over one third, compared with only $18 \%$ among White adolescent boys [5]. The National Institutes of Health and expert committees have called for research to identify reasons for these disparities and inform prevention efforts $[6,7]$. 
Inadequate physical activity contributes directly to risk for obesity and the development of chronic conditions such as hypertension and type 2 diabetes [8]. Most adolescents do not meet public health recommendations for physical activity and exceed recommendations for time spent in sedentary activity; again, racial and ethnic differences are apparent [4, 9-11]. Nationwide, less than one third of adolescents participating in the YRBSS had engaged in vigorous activity for at least 60 min per day in the week before the survey, and Black and Hispanic students were less likely than White students to engage in this healthy behavior [4]. Similarly, one third of students watched 3 or more hours of television on an average school day, and Black and Hispanic students were more likely than Whites to engage in this unhealthy behavior (the vigorous physical activity and hours of television of other ethnic/ racial groups were not compared) [4].

Social ecological models suggest that factors at multiple levels, including the neighborhood, school, family, peer, and individual, influence adolescents' health behaviors [12-14]. In particular, characteristics of the home and family environment have been associated with adolescents' weight [15] and physical and sedentary activity [16] in our previous work as well as in other research [9, 17-21]. Parents' activity levels (which includes modeling of physical activity) have been consistently positively associated with youth physical activity $[20,22]$. In our previous research, which comprehensively explored personal, friend, family, school, and neighborhood correlates of adolescent physical activity, characteristics of the family environment explained more variance in adolescents' moderate-to-vigorous activity levels than more distal ecological factors such as characteristics of school and neighborhood environments [16], setting the stage for the present study. Few studies have examined how home and family qualities such as providing support and resources (e.g., equipment) for activity may vary across ethnic and racial groups, or how their associations with activity may be moderated by race [23-25]. Ness and colleagues [2012], for example, found significantly more parental physical activity reported among Native American parents than White parents. Bauer and colleagues [2011] also found that parents of Asian (primarily Hmong) girls reported more support for physical activities than those in other groups. Different norms, values, religious practices, or other features of ethnic/racial communities may vary across groups and may affect parent support for their children's physical activity. A key remaining question is whether public health recommendations to enhance physical activity are equally relevant across ethnic/racial groups. Examining disparities in physical activity risk and protective factors for obesity in the homes of adolescents will provide useful information to better guide the development of interventions and recommendations for diverse families.

The present study, therefore, builds on previous work indicating the importance of home and family factors for adolescent physical activity and addresses two main research questions. First, are there differences across ethnic/racial groups in the family/home environments of adolescents with regards to parental modeling, supporting, and providing equipment for physical and sedentary activity? Second, are observed associations between the family/home environment and adolescents' BMI and physical and sedentary activity consistent across ethnic/racial groups? Uncovering answers to these questions will provide evidence to support culturally tailored recommendations to promote healthy activity levels in youth or, conversely, will indicate if existing recommendations are appropriate for diverse population groups.

\section{Methods}

\section{Study Design and Sample}

Data come from two linked cross-sectional, population-based studies, EAT 2010 (Eating and Activity in Teens) and Project F-EAT (Families and Eating and Activity in Teens), addressing BMI, dietary intake, activity, and related factors among adolescents. The EAT 2010 sample includes adolescent participants from 20 public middle and high schools in urban areas of Minnesota, which serve racially and economically diverse communities. During the 2009-2010 school year, 2,793 adolescents completed written surveys and had height and weight measured by trained research staff during required classes. Among adolescents who were at school on the days of survey administration, $96.3 \%$ had parental consent and chose to participate. As part of the EAT 2010 survey, participants were asked to provide contact information for up to two parents or guardians, and these adults (described here as parents) were mailed invitations to participate in Project FEAT within 3 months of student survey completion. Project FEAT written surveys were completed by 3,709 parents; $85 \%$ of adolescents had at least one parent respond, and among those who provided information on two parents, $68 \%$ had both parents participate. The University of Minnesota's Institutional Review Board (for EAT 2010 and Project F-EAT) and research boards of participating school districts (for EAT 2010) approved all study protocols. Additional details of the design of these two studies are available elsewhere $[5,15,26]$.

The sample for the present analysis includes all EAT 2010 adolescent participants who provided information on ethnicity/race and had at least one parent respond to the FEAT survey $(N=2,374)$. Among adolescents, $53.9 \%$ were female and their mean age was $14.4(\mathrm{SD}=2.0)$. Seven ethnic/racial groups were represented, including African American (23.2 \%), Asian (20.0\%), Hispanic (17.1\%), and White youth $(20.2 \%)$. Additional details of the adolescent sample are shown in Table 1. Among parents, $62.0 \%$ were female and their mean age was $42.4(\mathrm{SD}=8.4)$. Parents were 
Table 1 Characteristics of adolescent sample, $N=2,374$ (mean age= 14.4)

\begin{tabular}{lll}
\hline & Number & Percent \\
\hline Gender & & \\
$\quad$ Female & 1,278 & 53.8 \\
$\quad$ Male & 1,096 & 46.2 \\
Ethnicity/Race & & \\
White & 481 & 20.3 \\
African American & 550 & 23.2 \\
East African & 132 & 5.6 \\
Asian & 475 & 20.0 \\
Hispanic & 405 & 17.1 \\
Native American & 76 & 3.2 \\
Mixed/other & 255 & 10.7 \\
Parent education & & \\
Less than high school & 565 & 24.0 \\
High school/GED & 484 & 20.6 \\
Some college/training & 676 & 28.7 \\
Finished college & 422 & 17.9 \\
Advanced degree & 208 & 8.8 \\
\hline
\end{tabular}

categorized as primary versus secondary using the following information gleaned from the F-EAT survey of parents: (1) lives with adolescent more than half the time, (2) parent versus step-parent or other caregiver, and (3) female versus male parent [26-29]. By these criteria, all adolescents $(2,374)$ had data from a primary parent and 1,327 had data from an additional parent.

\section{Surveys and Measures}

The EAT 2010 survey was designed by the research team to assess numerous factors relevant to weight and related behaviors [5]. This instrument was modeled off the original Project EAT survey $[30,31]$ and included additional items. The full survey was pretested by 56 adolescents from diverse backgrounds to determine readability and relevance of new items and was reviewed by a team of experts in adolescent development, health disparities, nutrition, physical activity, and family relations. Following modifications based on initial feedback, the revised survey was pilot-tested with 129 adolescents and 1-week test-retest reliability was assessed. Final revisions to the survey were based on pilot test feedback and reliability findings.

The F-EAT survey was designed using similar methods. Items were drawn from the original Project EAT parent survey $[32,33]$, corresponding measures from the EAT 2010 survey, existing measures from the published literature, and newly created items to meet the study aims. Bicultural staff from the Wilder Research Foundation (www.wilderresearch.org) reviewed early drafts and provided feedback on cultural appropriateness for the ethnic/racial groups participating in the study, and three focus groups with a diverse sample of 28 parents were used to pretest the survey. The survey was finalized based on feedback from these groups. Two-week test-retest reliability was assessed by inviting a subset of parent participants to retake the survey for an additional incentive $(n=102)$. The final written F-EAT survey was professionally translated into Spanish, Somali, and Hmong, and these versions were sent to parents when the EAT 2010 participant indicated that the primary language spoken at home was not English. The survey was also administered by phone in Karen, Oromo, and Amharic as needed $(n=5)$.

Adolescent ethnicity/race was assessed on the EAT 2010 student survey with the item, "Do you think of yourself as (1) white, (2) black or African American, (3) Hispanic or Latino, (4) Asian American, (5) Hawaiian or Pacific Islander, (6) American Indian or Native American, or (7) other," and respondents were asked to check all that apply (test-retest agreement $=98-100 \%$ ). A second item was used to distinguish African Americans from other African groups: "Is your background any of the following?" Response categories included "Hmong, Cambodian, Vietnamese, Laotian, Somali, Ethiopian, Other, and none of the above" (test-retest agreement $=92 \%$ ). Those responding Somali or Ethiopian comprised a separate East African group, due to different cultural norms and the needs of these immigrant populations in the local area. Participants who indicated that they were White and another group were coded as the other group; those reporting more than one non-White group were coded as "mixed/other" for analysis, as in our previous work [5]. A very small number reported a Hawaiian or Pacific Islander background and were included in the mixed/other group.

\section{Independent Variables: Family/Home Activity Environment}

Six measures of the family/home environment were drawn from the F-EAT survey, to capture modeling, support, and equipment for both physical activity and television use. $\mathrm{Pa}$ rental modeling (i.e., parental hours of physical activity) was measured with two items from the Leisure Time Exercise Questionnaire [34] assessing hours of moderate (e.g., walking quickly, easy bicycling, and strength training) and vigorous physical activity (e.g., biking fast, running/jogging, and swimming laps) in a usual week (test-retest $r_{\text {moderate }}=.56$; test-retest $r_{\text {strenuous }}=.75$ ). Six responses ranged from 0 to 6 or more hours. These items have been significantly associated with standard activity and physiologic measures in reliability and validity studies with community samples of adolescents and adults $[34,35]$. Responses were coded as the midpoint of the given range, e.g., $1 / 2$ to $2 \mathrm{~h}$ a week was coded as $1.25 \mathrm{~h}$ for analysis, and responses for moderate and vigorous activity (MVPA) were summed. 
Two items were summed to reflect parental hours of supporting physical activity of their adolescent: "In a typical week, how many hours do you spend... Being physically active with your child (e.g., throwing a ball around, taking a walk or bike ride together)? Helping your child to be physically active (e.g., driving them to the gym or sport practice, watching them play a sport)?" (test-retest $r$ active $=.58$; test-retest $r_{\text {helping }}=.62$; Cronbach's alpha for two items $=.65$ ). Response options ranged from 0 to 6 or more hours and were re-coded as for physical activity. These items were combined into a single scale to be consistent with previous studies [36-38] and based on factor analysis indicating shared variance [38].

Five items were used to measure access to physical activity equipment in the home: "Do you have the following items in your home, yard, or apartment complex that would be available to your child? Stationary aerobic equipment; bicycle, skateboard, scooter, rollerskates/blades; basketball hoop; weight lifting equipment; interactive video games such as Wii Sport ${ }^{\circledR}$, Wii Fit ${ }^{\circledR}$, and Dance Dance Revolution ${ }^{\circledR}$ (yes/ no for each; test-retest agreement ranged from 80-89\%). Responses were summed to indicate $0-5$ items. These items were drawn from the Physical Activity and Media Instrument (PAMI), which has been shown to be a valid and reliable tool for assessing obesogenic home environments [39].

Parental total hours of TV viewing was measured with one item, "On an average day, how many hours do you spend watching TV, DVDs, or videos?" (test-retest $r=.78$ ), adapted from an existing reliable measure of adult sedentary activity [40]. Responses ranged from 0 to 5 or more (coded as $6 \mathrm{~h}$ for analysis) and were multiplied by 7 for weekly hours. Parental hours of TV viewing with their child was measured with one item, "In a typical week, how many hours do you spend... watching TV/movies together with your child?" (test-retest $r=.53$ ). Response options ranged from 0 to 6 or more hours per week and were re-coded as for physical activity.

Parents were asked how many they had of a variety of media devices in the home, including TV, VCR, or DVD player; $\mathrm{TiVo}^{\circledR}$ or Digital Video Recorder; computer or laptop; and video game system (test-retest correlations ranged from .73 to .90). Responses for each device were $0-4$ or more, and $\mathrm{TiVo}^{\circledR} / \mathrm{DVR}$ was truncated to 2 or more as this service typically works on multiple televisions. Items were summed for a single media device measure. Media device items also came from an existing instrument with acceptable psychometric properties [39].

Data from one parent was used to create each family/home variable. In cases where two parents responded to surveys, weekly hours of physical activity, supporting physical activity, total TV viewing, and TV viewing with child were taken from the parent with the higher value, on the premise that one parent providing this modeling or support (e.g., driving to soccer practice) was the construct of interest. Responses from two parents could not distinguish between activities done together (e.g., watching TV as a family) or separately and would greatly overestimate parental time spent doing physical activity or watching TV for adolescents with two parents reporting. Such overestimation would bias the analysis, as the proportion of adolescents with one versus two parents responding differed significantly across ethnic/racial groups (36.4-69.2 \%, $\left.X^{2}=169.3, p<.001\right)$. In contrast, reports on the number of physical activity items and media devices in the home were taken from the primary parent, on the assumptions that responses should not vary by reporter and the primary parent had accurate knowledge of the resources in the adolescent's home.

\section{Dependent Variables: Adolescent BMI, Physical Activity, and TV Viewing}

Three dependent variables were used in this analysis. Adolescent BMI was calculated from height and weight measurements obtained by study staff during in-school survey completion [weight in kilograms/(height in square meters)]. Using standardized procedures and calibrated instruments, weight to the nearest $.1 \mathrm{~kg}$ was measured without shoes, heavy outerwear, or other items (e.g., wallets), and height was assessed to the nearest $.1 \mathrm{~cm}$. BMI was converted to $z$-scores, standardized for sex and age, for statistical analysis.

Adolescent hours of moderate-to-vigorous physical activity (MVPA) were measured using the Leisure Time Exercise Questionnaire; responses and coding were the same as described above for parents although example activities were modified somewhat to ensure relevance for the adolescent participants (test-retest $r=0.73$ ) [35]. Adolescent hours of TV viewing were assessed with two items asking about hours spent watching TV, DVDs, or videos on an average weekday (MondayFriday) and weekend day (Saturday or Sunday). Seven response options ranged from 0 to $5+$ hours (coded as 6 for analysis) and combined to estimate weekly hours of viewing (test-retest $r=0.67$ ). These items were adapted from an existing television and video use measure which was moderately correlated $(r=0.54)$ with a 24-h recall [41].

\section{Covariates}

Adolescent gender and age were used as covariates in all analyses. Five levels of parental education reflected the higher level of education reported by either parent (less than high school, high school or general equivalency diploma (GED), some college or training after high school, finished college, or advanced degree). 


\section{Data Analysis}

Family/home environment variables, adolescent dependent variables, and covariates were described using means and frequencies. Analysis of variance was used to examine differences in family/home environment variables across the seven ethnic/racial groups (both with and without adjustment for parent education, which was strongly associated with ethnicity/race bivariately, $X^{2}=$ 680.3, $p<.001$ ), and post hoc tests compared each ethnic/racial group to each other group. Significant differences $(p<.05)$ among groups are noted in tables with alphabetic superscripts (those sharing a letter are not significantly different from each other). Multiple linear regression analysis modeled each continuous dependent variable based on each family/home environment variable, separately, adjusted for ethnicity/race, gender, age, and parent education.

In order to determine if the observed associations between family/home environment variables and each dependent adolescent variable were consistent across the seven ethnic/racial groups, interaction terms were added to each regression model (ethnicity/race by environment variable). In cases where $p$ values for these interaction terms were $<.10$, models were re-run stratified by ethnicity/race, adjusting for covariates. A more generous threshold than usual was selected $(p<.10)$ to permit a thorough exploration of trends across ethnic/ racial groups, including those with smaller numbers.

\section{Results}

Family/Home Environment and Adolescent BMI, MVPA, and TV Viewing

The mean BMI among adolescents was 23.7 ( $\mathrm{SD}=5.7)$. Adolescents engaged in $5.8 \mathrm{~h}$ of MVPA per week $(\mathrm{SD}=$ 4.8) and watched $17.1 \mathrm{~h}$ of television ( $\mathrm{SD}=12.0$; Table 2). Parents similarly reported more TV viewing and media devices in their environment than activityrelated behaviors and equipment (Table 2).

After adjusting for ethnicity/race, gender, age, and parent education, the family/home environment variables relevant to support of physical activity were significantly associated with adolescent MVPA in the expected direction (i.e., more parental modeling, support, and equipment in the home were associated with more hours of adolescent MVPA hours in the adolescent; Table 3). Likewise, family/home media variables were significantly associated with adolescent TV viewing. For example, each additional hour of
Table 2 Adolescent BMI, adolescent and parent activity, and family/ home environment variables

\begin{tabular}{|c|c|c|c|}
\hline & $\mathrm{N}$ & Mean (SD) & Range \\
\hline \multicolumn{4}{|l|}{ Adolescent } \\
\hline BMI & 2340 & $23.7(5.6)$ & $13.6-52.6$ \\
\hline Weekly hours of MVPA & 2376 & $5.8(4.8)$ & $0-16$ \\
\hline Weekly hours of TV viewing & 2369 & $17.1(12.0)$ & $0-42$ \\
\hline \multicolumn{4}{|l|}{ Parent } \\
\hline Weekly hours of MVPA ${ }^{\mathrm{a}}$ & 2356 & $5.1(4.5)$ & $0-16$ \\
\hline $\begin{array}{l}\text { Weekly hours of supporting } \\
\text { child's activity }^{\text {a }}\end{array}$ & 2360 & $3.4(3.4)$ & $0-14$ \\
\hline $\begin{array}{l}\text { Number of physical activity } \\
\text { equipment items } \\
\text { in the home }{ }^{\mathrm{b}}\end{array}$ & 2345 & $2.3(1.4)$ & $0-5$ \\
\hline Weekly hours of $\mathrm{TV}^{\mathrm{a}}$ & 2355 & $17.1(11.6)$ & $0-42$ \\
\hline $\begin{array}{l}\text { Weekly hours of TV viewing } \\
\text { with child }^{\mathrm{a}}\end{array}$ & 2353 & $2.8(2.2)$ & $0-7$ \\
\hline $\begin{array}{l}\text { Number of media devices } \\
\text { in the home }\end{array}$ & 2352 & $7.7(3.3)$ & $0-18$ \\
\hline
\end{tabular}

MVPA moderate-to-vigorous physical activity

${ }^{\text {a }}$ Higher value reported by either parent

${ }^{\mathrm{b}}$ Reported by primary parent

parent's watching TV with their adolescent was associated with approximately an additional half-hour of adolescent viewing $(\beta=.54, p<.001)$. Parental total TV viewing was also positively associated with adolescent BMI $z$-score $(\beta=.005, p=.016)$, and parental hours of TV viewing with their adolescent was marginally associated with adolescent BMI $z$-score $(\beta=.018, p=.078)$.

\section{Characteristics of Family/Home Environment Across Ethnic/Racial Groups}

As shown in Table 4, all family/home environment measures varied significantly across the seven ethnic/ racial groups included here. For example, parents' weekly hours of MVPA ranged from $3.6 \mathrm{~h}$ per week among East African parents to $6.2 \mathrm{~h}$ among White parents $(p<.05)$. Similarly, East African parents reported significantly fewer hours of total TV viewing $(9.5 \mathrm{~h}$ per week) compared to African American (22.1 h per week) and Native American parents (23.5 h per week).

No consistent patterns emerged among groups with regards to their family/home environments being more or less health promoting. For example, East African and Asian parents reported the least healthy activity environments but also had the healthiest media environments. This lack of consistency was visible even within domains: White parents had among the highest number of weekly MVPA hours and the most physical activity equipment, 
Table 3 Associations between parental and home environment and adolescent BMI, physical activity, and TV viewing (adjusted for gender, age, ethnicity/race, parent education)

\begin{tabular}{|c|c|c|c|}
\hline & Adolescent BMI $z$-score & Adolescent MVPA & Adolescent TV viewing \\
\hline \multicolumn{4}{|l|}{ Physical activity environment } \\
\hline Parent's weekly hours of MVPA & $\beta=.008, p=.123$ & $\beta=.09, p<.001$ & $\beta=.03, p=.608$ \\
\hline Parent's weekly hours of supporting activity & $\beta=.006, p=.355$ & $\beta=.22, p<.001 *$ & $\beta=-.11, p=.123$ \\
\hline Number of physical activity items in the home & $\beta=-.010, p=.551$ & $\beta=.23, p<.001 \sim$ & $\beta=-.05, p=.795$ \\
\hline \multicolumn{4}{|l|}{ Media environment } \\
\hline Parent's total weekly hours of TV & $\beta=.005, p=.016$ & $\beta=.00, p=.846 \sim$ & $\beta=.11, p<.001$ \\
\hline Parent's weekly hours of TV viewing with child & $\beta=.018, p=.078 \sim$ & $\beta=.06, p=.192$ & $\beta=.54, p<.001$ \\
\hline Number of media devices in the home & $\beta=.010, p=.179$ & $\beta=.03, p=.293^{*}$ & $\beta=.19, p=.017 \sim$ \\
\hline
\end{tabular}

Boldface type indicates statistical significance $(p<.05)$ for main effect

MVPA moderate-to-vigorous physical activity

${ }^{*} p<.05, \sim p<.10$ for interaction of family/home environment variable and ethnicity/race

but their hours of supporting their adolescent's physical activity were not significantly greater than most other groups.

In order to confirm that these associations were not due largely to differences in parental education (a proxy for economic status) across ethnicity/race, ANOVAs were re-run adjusting for parental education. The pattern of results was very similar in adjusted and unadjusted models.

\section{Effect Modification by Ethnicity/Race}

Interaction terms tested if the observed associations between characteristics of family/home environments and adolescent variables differed across ethnic/racial groups. For most associations, interaction terms were not statistically significant, indicating that estimates shown in Table 3 are applicable across ethnic/racial groups. However, of the 18 interaction tests, two were statistically significant and an additional four were near significant $(p<.10)$, suggesting effect modification beyond what would be expected due to chance. These six models were stratified by ethnicity/race to identify groups for which associations were present (or stronger), and adjusted for gender, age, and parental education. Findings are shown in Table 5 and described below.

\section{Associations Between Media Devices in the Home and Adolescent BMI z-score in Stratified Models}

Parental hours of TV viewing with their child was significantly related to adolescent BMI $z$-score among African American youth $(\beta=.046, p=.024)$, and these variables were marginally associated among East African youth $(\beta=.108, p=.088)$ in the expected direction. Of note, the slope estimates for Native American and mixed/other race youth were similar in magnitude to that of African American youth $(\beta=-.044$ and $-.047)$ but were contrary to hypotheses. These estimates did not approach statistical significance, possibly due to relatively small numbers in these groups.

\section{Associations Between Parent Support for Physical and Sedentary Behaviors and Adolescent MVPA in Stratified Models}

Associations between adolescent MVPA and parents' support, physical activity equipment in the home, parents' total hours of TV, and number of media devices all varied by ethnicity/ race. Parental support for their adolescent's activity was significantly associated with the adolescent's MVPA hours in most (African American, Asian, Hispanic, White, and mixed/ other) but not all ethnic/racial groups. In contrast, the availability of physical activity equipment was significantly associated with the adolescent's activity hours only among Asian and Hispanic youth (although again, East African youth had a similar slope estimate, $\beta=.48$ that did not achieve statistical significance in this sample). Parents' total hours of TV viewing were significantly related to adolescent MVPA only for Native American youth $(\beta=.08, p=.046)$ and in the opposite of the expected direction. Similarly, having more media devices in the home was significantly associated with more MVPA among adolescents of mixed/other race $(\beta=.21$, $p=.048)$.

\section{Associations Between Media Devices in the Home and Adolescent TV Viewing in Stratified Models}

For White youth, having more media devices in the home was associated with more TV viewing $(\beta=.40, p=.015)$. Associations between media devices and TV viewing did not achieve statistical significance in other ethnic/racial groups, but 
similarly large slope estimates were found for East African $(\beta=.61)$ and Native American youth $(\beta=-.56)$.

\section{Discussion}

Findings from this study indicate significant differences in the family and home characteristics of adolescents across seven different ethnic/racial groups, which supports limited previous studies [23-25], but do not point to any groups with consistently health-promoting environments with regards to activity. Generally speaking, a positive physical activity environment - characterized by parental modeling and support of physical activity and the presence of equipment - was associated with more MVPA among adolescents. Likewise, an environment of modeling and availability of equipment for media viewing was associated with more TV viewing time. For most models, interactions with ethnicity/race were not statistically significant. Therefore, while this study identified differences in the home environment across ethnicity/race, most associations between the environment and levels of activity in adolescents did not differ across ethnic/racial groups. These results suggest that most types of health promotion recommendations related to the home and family environment are relevant for diverse youth populations.

However, for some associations, particularly adolescent MVPA, several interactions between family/home variables and ethnicity/race were observed. These stratified models did not show a consistent pattern of stronger or weaker associations in any particular group; rather, findings from these models typically included a statistically significant relationship for one or two different groups in each model, including several findings in the opposite of the expected direction. The differences in statistical significance of associations across groups may be due to relatively small numbers in select ethnic/racial groups (e.g., Native American, $n=76$, and East African, $n=132$ ) or differences in standard errors for family/home environment variables across groups, or may be spurious results in a large number of tests. This pattern of findings may, however, reflect genuine differences in the role that family/home environment characteristics contribute to MVPA and media use among youth. For example, the presence of media devices in the home may not relate to more TV viewing among most minority groups in the way it does for White adolescents in the present sample and elsewhere [9, 18]. Further qualitative and quantitative research with diverse samples of adolescents and their families would be useful to understand nuances in the role of physical activity in different cultures and within different home environments. For example, an important first step would be to learn how different cultures interpret the 
Table 5 Associations between family/home environment characteristic and adolescent BMI, MVPA, and TV viewing, by ethnicity/race (adjusted for gender, age, and parent education)

\begin{tabular}{|c|c|c|c|c|c|c|}
\hline & \multicolumn{2}{|l|}{ Adolescent BMI } & \multicolumn{2}{|c|}{ Adolescent MVPA } & \multirow[b]{2}{*}{$\begin{array}{l}\text { Number of } \\
\text { media devices }\end{array}$} & \multirow{2}{*}{$\begin{array}{l}\text { Adolescent TV viewing } \\
\begin{array}{l}\text { Number of } \\
\text { media devices }\end{array}\end{array}$} \\
\hline & $\begin{array}{l}\text { Parent's TV } \\
\text { viewing with } \\
\text { child }\end{array}$ & $\begin{array}{l}\text { Parent's } \\
\text { supporting } \\
\text { activity }\end{array}$ & $\begin{array}{l}\text { Number of } \\
\text { activity items }\end{array}$ & $\begin{array}{l}\text { Parent's total } \\
\text { hours of TV }\end{array}$ & & \\
\hline African American & $\beta=.046, p=.024$ & $\beta=.20, p<.001$ & $\beta=.29, p=.052$ & $\beta=-.01, p=.492$ & $\beta=-.02, p=.789$ & $\beta=.12, p=.486$ \\
\hline Asian & $\beta=.021, p=.379$ & $\beta=.16, p=.020$ & $\beta=.43, p=.007$ & $\beta=-.03, p=.115$ & $\beta=.06, p=.352$ & $\beta=.16, p=.371$ \\
\hline East African & $\beta=.108, p=.088$ & $\beta=.08, p=.532$ & $\beta=.48, p=.098$ & $\beta=-.03, p=.532$ & $\beta=-.13, p=.390$ & $\beta=.61, p=.154$ \\
\hline Hispanic & $\beta=.-.009, p=.717$ & $\beta=.12, p=.050$ & $\beta=.43, p=.010$ & $\beta=-.02, p=.352$ & $\beta=.14, p=.055$ & $\beta=.31, p=.119$ \\
\hline Native American & $\beta=-.044, p=.452$ & $\beta=.07, p=.563$ & $\beta=-.10, p=.675$ & $\beta=.08, p=.046$ & $\beta=.15, p=.290$ & $\beta=-.56, p=.131$ \\
\hline White & $\beta=.032, p=.158$ & $\beta=.42, p<.001$ & $\beta=-.23, p=.194$ & $\beta=.02, p=.385$ & $\beta=-.12, p=.085$ & $\beta=.40, p=.015$ \\
\hline Mixed/other & $\beta=-.047, p=.141$ & $\beta=.33, p<.001$ & $\beta=-.03, p=.913$ & $\beta=.03, p=.320$ & $\beta=.21, p=.048$ & $\beta=-.29, p=.254$ \\
\hline
\end{tabular}

Boldface type indicates statistical significance $(p<.05)$

idea of "support" for physical activity. Such qualitative work would contribute to better measurement of physical activity constructs in the home environment and eventually allow for tailored recommendations for health promotion, which may be an important tool for health professionals working with youth.

Socio-economic differences may account for the number of media items and the amount of physical activity equipment in the home, and these measures were correlated with each other. Survey questions were worded to include "home, yard, or apartment complex" to capture a range of living situations, and models were adjusted for parental education as a measure of socio-economic status. However, these steps may not have fully accounted for differences across groups, which may contribute to this study's mixed findings. That is, families with limited discretionary income may purchase equipment only when need is great or there is a high likelihood of frequent use by family members; families with greater resources may make such purchases more frivolously. For example, the presence of activity equipment in the homes of Asian and Hispanic youth (and African American and East African, though not significantly) was associated with more physical activity; on average, these groups have lower education and greater poverty than White families in the area in which this study was conducted [42]. Further research with more comprehensive assessment (e.g., in-home qualitative interviews) of influences within the home physical activity environments of minority families is warranted to disentangle these issues [43].

Beyond differences in economic status, additional neighborhood or community characteristics may influence adolescents' weight and related behaviors and may operate through their influence on the family/home environment, in keeping with the social ecological models on which this work is based [12-14]. Minnesota schools are highly segregated with regards to ethnicity/race [44]. Indeed, in the present dataset, $25 \%$ of Native American students came from a single school (out of 20 participating schools), over half of East African students were sampled from two schools, and almost two thirds of Hispanic students came from five schools. The physical and social environments in which families are situated may affect physical activity and related behaviors among parents and adolescents, for example, by offering safe public parks, organized sports teams, proximity to gyms or other active recreational spaces such as bike paths, and a low crime rate [45]. Disentangling the complex mix of characteristics in neighborhoods, ethnic/racial communities, families, and individuals presents a substantial challenge; due to the distribution of race groups across participating schools, such an analysis was not feasible in this study. Future studies with diverse samples in more integrated communities will be important for understanding the unique role of the family/home environment aside from community influences.

In this examination of ethnicity/race, BMI and activity, immigration and degree of acculturation to mainstream US culture may also be relevant [24, 46]. Immigrants and refugees typically arrive to the USA with healthier behaviors than the average American, but overtime, their health risks often reach or exceed that of the general US population [47, 48]. One reason for this disparity is lower physical activity among firstand second-generation immigrants than more acculturated third-generation and non-immigrant populations [49-52]. Access to resources, adolescents' role in the family, and social norms around activity may differ and contribute to the lack of activity. Because immigrant status was almost fully confounded with ethnicity/race (only Hispanic, Asian, and East African groups had a sizable proportion of youth born outside the USA), this construct was not included as a covariate in analytic 
models. Additional qualitative research may be particularly beneficial in understanding the role of acculturation and culture in the family/home environment for physical activity $[53,54]$.

\section{Limitations and Strengths}

This study makes use of a large and diverse sample of adolescents and their parents, with adequate numbers of participants in seven ethnic/racial groups for statistically valid analysis. As most studies of ethnic/racial differences in this area compare only two to three groups $[10,11,23,46,54,55$, Thul et al. Physical activity comparisons among Minnesota adolescents of Somali, other non-Hispanic Black and White racial/ ethnic backgrounds, Under review], this sample provides an advantage over much of the existing work. Data collection included surveys of both the adolescents and their parents, which is a novel strength, and investigator-measured BMI was used rather than self-report for the adolescent outcome. The range of family/home environment measures of relevance to both MVPA and TV viewing - reflecting modeling, support, and physical resources - is also an advantage, as it permits exploration of various elements of the overarching construct of the physical activity environment, which can result in specific and concrete health promotion recommendations.

However, this study is also subject to several limitations. While broad, items measuring the home environment may also have limitations. Specifically, items measuring family support for adolescent physical activity and sedentary behaviors were not standardized measures nor were they validated for diverse ethnic/racial populations. In addition, many of the home environment constructs were measured with single items. However, these items were taken from previous surveys which found high test-retest reliability in these items [56] and were pilot-tested with diverse samples of parents and adolescents. Additionally, all items (with the exception of adolescent BMI) were assessed via self-report. Although several items were drawn or adapted from existing instruments with acceptable reliability and validity [34-39, 41], they were not validated through objective measurements in the present study. Objective measures of these items would potentially be more valid. Although the sample was adequate to test for differences even in relatively small ethnic/racial groups, some groups were too small to permit deeper analyses examining gender differences within ethnic/racial groups, the possible importance of matched parent/ child gender for modeling or support across groups, or the significance of discordant responses from two parents. Differences in sample size and heterogeneity by ethnicity/race may also have limited our ability to detect significant associations in the present study. Finally, the cross-sectional nature of the study design limits interpretation; while the provision of parental support or equipment may contribute to activity in youth, it is also possible that adolescents' interest and involvement in activities lead to parental support (such as driving to events) or purchase of relevant equipment.

\section{Conclusions}

In general, findings from the current study indicate that health promotion recommendations regarding modeling and supporting physical activity rather than TV viewing are relevant for adolescents without regard to racial or ethnic background. However, health care providers or other professionals working with families and adolescents, advising families on particular health behaviors (such as increasing MVPA), or working with specific ethnic/racial groups may take note of several ways in which associations between the home environment (e.g., the presence of media devices) and behavior differ across ethnic/racial groups, suggesting the importance of cultural sensitivity in discussing these topics, and taking time to explore attitudes and practices around activity in the home and family. Culturally tailored recommendations may be appropriate for select issues and audiences. For example, limiting the number of media devices available in the home may be an especially important strategy regarding TV time among White youth. Also, recommending different types of physical activity to do in the home may be appropriate for East African, Asian, or Hispanic adolescents, who tend to have less in-home physical activity equipment or who may particularly benefit from alternative suggestions for being physically active on a family level (e.g., family walk and family game participation such as soccer).

In addition, future research on the home physical activity environments of diverse families would benefit from mixed methods studies. Utilizing objective measures of equipment within the home physical activity environment and exploring a greater number of family/home influences on weight and activity (e.g., sibling behaviors and responsibility for work around the home) will strengthen this body of work. Qualitative interviews to get families' own perspectives about specific activities of interest, cultural values surrounding sport and activity, perceived barriers to physical activity, and the perceived mechanisms underlying associations found here would yield a more comprehensive picture of the homes of diverse families and aid in the development of tailored, culturally sensitive recommendations. Finally, structural barriers such as economic status intersect with ethnicity/race to limit familylevel physical activity. Understanding how this mechanism operates across ethnic/racial groups is imperative for creating successful health promotion interventions. 
Acknowledgments This project was supported by the National Heart, Lung, and Blood Institute under grants R01HL084064 and R01HL093247 and by the Children's Discovery Fund of the University of Minnesota's Department of Pediatrics. The content is solely the responsibility of the authors and does not necessarily represent the official views of the National Institutes of Health or the University of Minnesota. The funding bodies had no role in study design; collection, analysis, or interpretation of data; report writing, or decisions to submit manuscripts. Conflict of Interest Marla Eisenberg, Nicole Larson, Jerica Berge, Chelsey Thul, and Dianne Neumark-Sztainer declare that they have no conflicts of interest relating to this research.

Informed Consent Statement All procedures followed were in accordance with the ethical standards of the responsible committee on human experimentation (institutional and national) and with the Helsinki Declaration of 1975 , as revised in 2000 . Informed consent was obtained from all participants for being included in the study.

\section{References}

1. Wang Y, Orleans CT, Gortmaker S. Reaching the healthy people goals for reducing childhood obesity: Closing the energy gap. Am J Prev Med. 2012;42:437-44.

2. Ogden C, Carroll M, Kit B, Flegal K. Prevalence of obesity and trends in body mass index among US children and adolescents, 19992010. JAMA. 2012;307:483-90.

3. Freedman DS. Obesity—United States, 1988-2008. MMWR Surveill Summ. 2011;60(Suppl):73-7.

4. Eaton DK, Kann L, Kinchen S, et al. Youth risk behavior surveillance-United States, 2011. MMWR Surveill Summ. 2012;61:1162.

5. Neumark-Sztainer D, Wall MM, Larson N, et al. Secular trends in weight status and weight-related attitudes and behaviors in adolescents from 1999 to 2010. Prev Med (Baltimore). 2012;54:77-81. doi: 10.1016/j.ypmed.2011.10.003.

6. National Institutes of Health Obesity Research Task Force (2011) Strategic plan for NIH obesity research.

7. National Heart Lung and Blood Institute (2007) Working group report on future research directions in childhood obesity prevention and treatment. http://www.nhlbi.nih.gov/meetings/workshops/ childobesity/ index.htm\#summarypreventionpanel.

8. U.S. Department of Health and Human Services (2008) 2008 Physical Activity Guidelines. Washington DC

9. Sisson SB, Broyles ST. Social-ecological correlates of excessive TV viewing: Difference by race and sex. J Phys Act Health. 2012;9:449-55.

10. Schuster MA, Elliott MN, Kanouse DE, et al. Racial and ethnic health disparities among fifth-graders in three cities. N Engl J Med. 2012;367:735-45. doi:10.1056/NEJMsa1114353.

11. Gortmaker SL, Lee R, Cradock AL, et al. Disparities in youth physical activity in the United States: 2003-2006. Med Sci Sports Exerc. 2012;44:888-93. doi:10.1249/MSS.0b013e31823fb254.

12. Rew L. Adolescent health: a multidisciplinary approach to theory, research and intervention. Thousand Oaks: Sage Publications; 2005.

13. Bronfenbrenner U. The ecology of human development: experiments by nature and design. Cambridge: Harvard University Press; 1979.

14. Sallis JF, Owen N, Fisher E (2008) Ecological models of health behavior. In: Glanz K, Rimer B, Viswanath K, editors. Heal. Behav. Heal. Educ. Theory, Res. Pract., 4th ed. San Francisco: Josey-Bass; p. 465-85

15. Larson NI, Wall MM, Story MT, Neumark-Sztainer DR. Home/family, peer, school, and neighborhood correlates of obesity in adolescents. Obesity (Silver Spring). 2013;21:1858-69. doi:10. 1002/oby. 20360.
16. Graham DJ, Wall MM, Larson N, Neumark-Sztainer D. Multicontextual correlates of adolescent leisure-time physical activity. Am J Prev Med. 2014;46:605-16. doi:10.1016/j.amepre.2014. 01.009.

17. Patnode CD, Lytle LA, Erickson DJ, et al. Physical activity and sedentary activity patterns among children and adolescents: A latent class analysis approach. J Phys Act Health. 2011;8:457-67.

18. Sirard JR, Laska MN, Patnode CD, et al. Adolescent physical activity and screen time: associations with the physical home environment. Int J Behav Nutr Phys Act. 2010;7:82. doi:10.1186/1479-5868-7-82.

19. Sallis JF, Prochaska JJ, Taylor WC. A review of correlates of physical activity of children and adolescents. Med Sci Sports Exerc. 2000;32: 963-75.

20. Ferreira I, van der Horst K, Wendel-Vos W, et al. Environmental correlates of physical activity in youth - A review and update. Obes Rev. 2007;8:129-54. doi:10.1111/j.1467-789X.2006.00264.x.

21. Jiménez-Pavón D, Fernández-Alvira JM, te Velde SJ, et al. Associations of parental education and parental physical activity (PA) with children's PA: The ENERGY cross-sectional study. Prev Med (Baltimore). 2012;55:310-4. doi:10.1016/j.ypmed.2012.07.011.

22. Berge JM, Saelens B. Familial influences on adolescents' eating and physical activity behaviors. Adolesc Med State Art Rev. 2012;23: 424-39.

23. Ness M, Barradas DT, Irving J, Manning SE. Correlates of overweight and obesity among American Indian/Alaska Native and NonHispanic White children and adolescents: National Survey of Children's Health, 2007. Matern Child Health J. 2012;16 Suppl 2: 268-77. doi:10.1007/s10995-012-1191-8.

24. Bauer KW, Neumark-Sztainer D, Fulkerson JA, Story M. Adolescent girls' weight-related family environments, Minnesota. Prev Chron Dis. 2011;8:A68.

25. McMinn AM, van Sluijs EMF, Nightingale CM, et al. Family and home correlates of children's physical activity in a multi-ethnic population: The cross-sectional Child Heart and Health Study in England (CHASE). Int J Behav Nutr Phys Act. 2011;8:11. doi:10. 1186/1479-5868-8-11.

26. Neumark-Sztainer D, Maclehose R, Loth K, et al. What's for dinner? Types of food served at family dinner differ across parent and family characteristics. Public Health Nutr. 2014;17:145-55. doi:10.1017/ S1368980012004594.

27. Berge JM, Maclehose R, Loth K, et al. Parent conversations about healthful eating and weight: Associations with adolescent disordered eating behaviors. JAMA Pediatr. 2013;167:746-53.

28. Berge JM, Maclehose R, Loth K, et al. Family meals. Associations with weight and eating behaviors among mothers and fathers. Appetite. 2012;58:1128-35.

29. Berge JM, Wall MM, Larson N, et al. The unique and additive associations of family functioning and parenting practices with disordered eating behaviors in diverse adolescents. J Behav Med. 2014;37:205-17.

30. Neumark-Sztainer D, Croll J, Story M, et al. Ethnic/racial differences in weight-related concerns and behaviors among adolescent girls and boys: Findings from Project EAT. J Psychosom Res. 2002;53:963-74.

31. Neumark-Sztainer D, Wall M, Guo J, et al. Obesity, disordered eating, and eating disorders in a longitudinal study of adolescents: How do dieters fare 5 years later? J Am Diet Assoc. 2006; 106:55968. doi:10.1016/j.jada.2006.01.003.

32. McGuire M, Hannan PJ, Neumark-Sztainer D, et al. Parental correlates of physical activity in a racially/ethnically-diverse adolescent sample. J Adolesc Health. 2002;30:253-61.

33. Hanson NI, Neumark-Sztainer D, Eisenberg ME, et al. Associations between parental report of the home food environment and adolescent intakes of fruits, vegetables, and dairy foods. Public Health Nutr. 2005;8:77-85.

34. Godin G, Shephard RJ. A simple method to assess exercise behavior in the community. Can J Appl Sport Sci. 1985;10:141. 
35. Sallis JF, Buono MJ, Roby JJ, et al. Seven-day recall and other physical activity self-reports in children and adolescents. Med Sci Sports Exerc. 1993;25:99-108.

36. Sallis JF, Prochaska JJ, Taylor WC, et al. Correlates of physical activity in a national sample of girls and boys in grades 4 through 12. Health Psychol. 1999;18:410-5.

37. Ommundsen Y, Page A, Ku P, Cooper AR. Cross-cultural, age and gender validation of a computerised questionnaire measuring personal, social and environmental associations with children 's physical activity : the European Youth Heart Study. 2008;14:1-14. doi: 10. 1186/1479-Received

38. Welk GJ, Wood K, Morss G. Parental influences on physical activity in children : An exploration of potential mechanisms. Pediatr Exerc Sci. 2003;15:19-33.

39. Sirard JR, Nelson MC, Pereira MA, Lytle LA. Validity and reliability of a home environment inventory for physical activity and media equipment. 2008;10:1-10. doi: 10.1186/1479-Received

40. Wolf A, Hunter D, Colditz GA, et al. Reproducibility and validity of a self-administered physical activity questionnaire. Int J Epidemiol. 1994;23:991-9.

41. Gortmaker SL, Peterson K, Wiecha J, et al. Reducing obesity via a school-based interdisciplinary intervention among youth: Planet Health. Arch Pediatr Adolesc Med. 1999;153:409-18.

42. Macartney S. American community survey briefs: Child poverty in the United States 2009 and 2010: Selected Race Groups and Hispanic Origin. 2011.

43. Dubay LC, Lebrun LA. Health, behavior, and health care disparities: Disentangling the effects of income and race in the United States. Int J Health Serv. 2012;42:607-25.

44. Hawkins B, Boyd C. Twin Cities-area schools more segregated than ever. MinnPost. 2008.

45. Wall MM, Larson NI, Forsyth A, et al. Patterns of obesogenic neighborhood features and adolescent weight: A comparison of statistical approaches. Am J Prev Med. 2012;42:e65-75. doi:10. 1016/j.amepre.2012.02.009.
46. Franzen L, Smith C. Differences in stature, BMI, and dietary practices between US born and newly immigrated Hmong children. Soc Sci Med. 2009;69:442-50. doi:10.1016/j.socscimed. 2009.05.015.

47. Oza-Frank R, Cunningham S. The weight of US residence among immigrants: A systematic review. Obes Rev. 2010;11:271-80.

48. Lassetter JH, Callister LC. The impact of migration on the health of voluntary migrants in Western societies: A review of the literature. J Transcult Nurs. 2009;20:93-104.

49. Singh GK, Yu SM, Siahpush M, Kogan MD. High levels of physical inactivity and sedentary behaviors among US immigrant children and adolescents. Arch Pediatr Adolesc Med. 2008;162:756-63.

50. Gerber M, Barker D, Puhse U. Acculturation and physical activity among immigrants: A systemic review. J Public Health. 2012;20: 313-41.

51. Taverno Ross S, Francis L, BeLue R, Viruell-Fuentes E. Associations between physical activity and overweight among U.S. youth by immigrant generation: Results from the 2007 National Survey of Children's Health. J Phys Act Health. 2012;9:840-8.

52. Liu J, Probst JC, Harun N, et al. Acculturation, physical activity, and obesity among Hispanic adolescents. Ethn Health. 2009;14:509-25.

53. Thul C. Exploring intersectionality in physical activity spaces among Somali females: Implications for programming. Minneapolis (MN): University of Minnesota; 2012.

54. Wieland M, Tiedje K, Meiers S, et al. Perspectives on physical activity among immigrants and refugees to a small urban community in Minnesota. J Immigr Minor Heal. 2013. doi:10.1007/S10903-0139917-2.

55. Stang J, Kong A, Story M, et al. Food and weight-related patterns and behaviors of Hmong adolescents. J Am Diet Assoc. 2007;107:93641. doi:10.1016/j.jada.2007.03.003.

56. Davison KK. Activity-related support from parents, peers, and siblings and adolescents' physical activity: Are there gender differences? J Phys Act Health. 2004;1:363-76. 